\title{
Expected Genetic Gain for several Quantitative Traits in Alfalfa (Medicago sativa L.)
}

\author{
Hassan MONIRIFAR \\ East Azarbaijan Research Center for Agriculture and Natural Resources, Agronomy and Plant Breeding Department, \\ Tabriz,Iran;monirifar@yahoo.com
}

\begin{abstract}
In order to determine genetic gain for some quantitative traits in alfalfa ecotypes an experiment was conducted during cropping seasons of 2001-2007 at East Azarbaijan Agricultural and Natural Resources Research Center, Tabriz, Iran. Twenty nine native ecotypes collected from northwest of Iran and an improved variety were used in a polycross nursery. A randomized complete block design was used with 12 replications to ensure the random mating in the polycross nursery. The 30 half-sib families resulted from polycross nursery were planted individually in pots and 30 day old seedlings transplanted in the field and various traits were measured for three cropping seasons in a polycross test. The results of data analysis showed large variations among ecotypes for the traits studied. This indicates that successful selection for desired traits among their progenies is possible. Based on general combining ability, especially for fresh and dry yield, several ecotypes, including 'Satellou', 'Gara-yonje', 'Almard,' 'Legan', 'Baftan', 'Khaje, 'Sivan', 'Ilan jouj, 'Dizaj Safar Ali', 'Khosrovang' and 'Garababa' were selected as promising parents for developing synthetic variety. The narrow-sense heritability values for fresh yield, dry matter, plant height, fresh leaf to stem and dry leaf to stem ratios were about 60\%, 59\%, 50\%, 11\% and 19\%, respectively. Using selection intensity of $30 \%$, an increase in fresh yield and dry matter yields were estimated to be 3.2 and $1.58 \mathrm{t} /$ ha, respectively.
\end{abstract}

Keywords: alfalfa, general combining ability, improvement, polycross

\section{Introduction}

Alfalfa (Medicago sativa L.) is a widely grown perennial forage legume in the world. It produces forage of high nutritional quality, has positive influences on soil fertility and may be used in a number of different forms (Tucak et al., 2008). It is an autotetraploid, open-pollinated species characterized by tetrasomic inheritance with multiple allelism and is apt to pronounced to inbreeding depression (Barcaccia et al., 1999).

Alfalfa is the most important perennial forage crop plant in Iran. Presently, it is grown on more than 616,000 ha of arable land, mainly in west and northwestern of the country. Ecotypes and landraces of alfalfa are still widely found in different regions of its provinces.

Crop improvement, through plant breeding, is greatly depended upon their genetic variation. Familiarity with the type of gene action, the extent of variation and the heritability of its traits are essential for choosing appropriate breeding strategies. Such knowledge may also suggest the ways to use germplasm to create new varieties (Bowley and Christie, 1981). The general objective in breeding of cross-pollinated perennial forage has so far been to develop improved synthetic populations (Aastveit and Aastveit, 1990; Nguyen and Sleper, 1983). The characters of greatest interest for improvement are in most cases forage yield and quality, persistency, seed yield, and stability over the years and locations. These characters are all quan- titative showing continuous variation in genetically heterogeneous populations and being highly influenced by different environmental factors. In order to plan an effective program, information on the extent and nature of the genetic variation and co-variation of the various characters within the base population is necessary. Thus, progeny testing is used to separate the additive and non-additive genetic variations (Aastveit and Aastveit, 1990; BolanosAguilar et al., 2000).

The most common systems of mating and progeny testing of perennial forage are open-polination, polycross, pair matings, and top-crossing (Aastveit and Aastveit, 1990). Half-sib (HS) matings are commonly used in forage breeding to: a) evaluate general combining abilities of parents for synthetic cultivar development; b) recombine selected entries in recurrent selection programs, and c) estimate genetic variability, heritability, and genetic advance in quantitative genetic studies (Nguyen and Sleper, 1983).

There have been a number of studies on general combining ability and using polycross in alfalfa. Goplen and Gossen (1994) used polycross to register AC Nordica alfalfa which was intended as a special-purpose cultivar for high snowfall areas of Canada. Dukic (1992) studied the seed production of 17 alfalfa genotypes in a polycross system. The progenies of some genotypes were significantly superior in seed yield and yield stability. They are assumed to have appropriate combining ability. Smolikova et al. (1991) evaluated a collection of alfalfa for 43 qualitative 
110

and quantitative traits, and some 12 of these genotypes were selected for a polycross. Polycross progeny test were performed to GCA and select components for synthesis. Halagic et al. (1992) concluded that production of synthetic forage like 'Marina' and 'Posavina' varieties can be accomplished by the use of polycross technique. 'Prista3' and 'Prista4', the Bulgarian varieties, were also produced by the polycross method. The former exceeds the standard Nadezhda 2 in dry matter yield by $18.7 \%$ and in seed yield by $15.4 \%$, while the latter exceeds it by, $13.7 \%$ and $19.2 \%$ respectively and is highly suitable for seed production. Gasaneko and Filatova (1980) obtained a synthetic population by the polycross method using individual biotypes of F2 and F3 inter-specific and inter-varietals hybrid during 1976-1978. The synthetic populations gave high yields of green matter.

This study was undertaken to estimate the genetic variation for some quantitative traits in several alfalfa ecotypes of Azarbaijan, Iran and determine their expected genetic gain.

\section{Materials and methods}

This study was carried out during growing seasons of 2001-2007 at the East Azarbaijan Agriculture and Natural Resources Research Center (AZARAN), Iran. Twentynine alfalfa native ecotypes from north west of Iran and one improved cultivar were used to establish the base population in 2002(Tab. 1). Ecotypes 1 to 29 were collected in 2001 from local farmers that had been planting their seed for at least 30 years. They were planted at AZARAN in polycross nursery on 2002. Complete isolation, 12 replication and honeybees used in polycross nursery. Polycross seeds were harvested from maternal rows.

The resulting half-sib (HS) progenies were planted in a green house at AZARAN on 15 March 2004, in individual pots containing a mixture of sandy-loam soil, peat and sand with 2:1:1 ratios. From each HS family, 135 plants were transplanted into the field at the AZARAN in 2004. In each plot, $45 \mathrm{HS}$ plants were transplanted in 3-row plot ( 15 plants in each row) $0.5 \mathrm{~m}$ apart and $3 \mathrm{~m}$ long.

The trial was established in a randomized block design with three replications. First year was considered for uniformity. During the next three-year plant height $(\mathrm{PH})$, number of shoot (NS), plant fresh weight (PFW), plant dry weight (PDW), leaf fresh and dry weight to stem fresh and dry weight, (LFW/SFW) and (LDW/SDW) ratios were measured. PFW was obtained by hand cutting of plants at approximately $5 \mathrm{~cm}$ above the ground and weighing by electronic balance. To determine PDW, fresh samples of randomly chosen plants were taken from each plot and placed into paper bags. The samples were then weighed and dried at $105^{\circ} \mathrm{C}$ for $24 \mathrm{~h}$ to assess average dry matter content (DMC). PDW were calculated by $\mathrm{DMC} \times \mathrm{PFW} / 100$ formula. Total yearly PFW and PDW for each plant were determined by summing up the biomass yield from each cut during each year. NS of individual plants was recorded directly following cuttings. Prior to cuttings, $\mathrm{PH}$ was measured from the ground to the top of the inflorescence. The mean of PH, NS, (LFW/SFW) and (LDW/SDW), and the sum of PFW and PDW for each year were used for analysis.

\section{Statistical analysis}

Statistical analyses were carried out using procedures from the SAS program (1995). About 2000 individual plants were used to calculate Pearson's correlation coefficients among traits.

Data were subjected to analysis of variance using the model:

$$
X_{i j k}=\mu+B_{i}+H S_{j}+(B H S)_{i j}+Y_{k}+(H S Y)_{j k}+(B Y)_{i k}+\varepsilon_{i j k}
$$

Where $i=1 . ., r ; j=1 . ., f ; k=1 . ., y ; X_{i j k}=$ observed phenotypic value of half-sib family $j$ in year $k$ for block $i$; $\mu=$ grand mean; $B=$ the $i^{\text {th }}$ block effect; $H S_{j}$ the $j^{\text {th }}$ family effect; $(B H S)_{i i}=$ block $\times$ half-sib family effect; $Y_{k}=$ the $k^{\text {th }}$ year effect; $(H S Y)_{j k}=$ half-sib family $\times$ year interaction effect; $(B Y)_{i k}=$ block $\times$ year interaction effect and $\varepsilon_{i j k}$ is the is the variation among $\mathrm{n}$ individual plants within plots or residual. Variance components estimated by computing appropriate linear functions of the mean squares as determined from the mean square expectations (Tab. 2).

With non-inbred parents from a random mating population, the genetic variance among HS families is equal to covariance of HS and one-forth of the additive genetic variance, assuming there are no additive $\times$ additive types of epistatic variance; i.e., $\sigma_{F}^{2}=\operatorname{Cov}(H S)=1 / 4 \sigma_{\mathrm{A}}^{2}$ (Nguyen and Sleper, 1983). With corresponding the familyx year interaction variances are equal to one-forth of the additive genetic xyear (Martzinger and Kemp Thorne, 1956).

Narrow-sense heritability on a phenotypic mean basis averaging over replications and years estimated as (Nguyen and Sleper, 1983):

$$
h_{P F M}^{2}=\frac{\sigma_{F}^{2}}{\sigma_{F}^{2}+\frac{\sigma_{R F}^{2}}{y}+\frac{\sigma_{F Y}^{2}}{(r f / f-l)}+\frac{\sigma^{2} e}{r y}}
$$

The expected response to selection per cycle is given by $R=k h^{2} \sigma=h^{2} S$, where $\mathrm{k}$ is the selection intensity, $h^{2}$ the heritability value, $\sigma$ the square root of phenotypic variance, $S$ the mean phenotypic value of selected plants (Falconer, 1983). According to Nguyen and Sleper (1983), the expected response to selection among half-sib families predicted. 


\section{Results and discussion}

The ANOVA for the 30 half- sib families of alfalfa is shown in Tab. 3. It showed a highly significant half-sib family effect $(\mathrm{P}<0.01)$ on all the traits evaluated. The year effect was also highly significant for all traits, except for plant fresh and dry weight $(\mathrm{P}<0.01)$.

Since only a wide genetic base gives the opportunity to select genotypes with a trait of interest, it is essential to understand the extent and distribution of genetic variation. This information is particularly important in alfalfa which

Tab. 1. Origins and local names of the alfalfa ecotypes under study to determine expected genetic gain

\begin{tabular}{|c|c|c|}
\hline Ecotype & Origin & Name \\
\hline 1. & Jolfa & 'Marzad' \\
\hline 2. & Kaleibar & 'Gran-chay' \\
\hline 3. & Ahar & 'Leghan' \\
\hline 4. & Marand & 'Zonorag' \\
\hline 5. & Marand & 'Sivan' \\
\hline 6. & Oskou & 'Khor-khor' \\
\hline 7. & Tabriz & 'Satellou' \\
\hline 8. & Malekan & 'Smail-abad' \\
\hline 9. & Maragheh & 'Koul-tapa' \\
\hline 10. & Ajab-shir & 'Almalou' \\
\hline 11. & Maragheh & 'Kordadeh' \\
\hline 12. & Tabriz & 'Sefidkhan' \\
\hline 13. & Bostan-abad & 'Gara-baba' \\
\hline 14. & Hasht-roud & 'Zolbin' \\
\hline 15. & Hasht-roud & 'Zavie' \\
\hline 16. & Hasht-roud & 'Seviar' \\
\hline 17. & Hasht-roud & 'Akram-abad' \\
\hline 18. & Mianeh & 'Balsin’ \\
\hline 19. & Bostan-abad & 'Bash-kand' \\
\hline 20. & Bostan-abad & 'Ein-aldin’ \\
\hline 21. & Sarab & 'Baftan' \\
\hline 22. & Sarab & 'Ilan-jough' \\
\hline 23. & Heris & 'Khaje' \\
\hline 24. & Heris & ‘Goravan’ \\
\hline 25. & Varzegan & 'Dizaj-safarali' \\
\hline 26. & Ahar & 'Kordlou' \\
\hline 27. & Varzegan & 'Khosrovanagh' \\
\hline 28. & Varzegan & 'Chalnab' \\
\hline 29. & Varzegan & 'Almard' \\
\hline 30. & Tabriz & 'Gara-yonje'h \\
\hline
\end{tabular}

Tab. 2. Analysis of variance based on plot mean

\begin{tabular}{ccc}
\hline Source & d.f. & Expected mean squares \\
\hline Replications (R) & $(r-1)$ & \\
Families (F) & $(f-1)$ & $\sigma_{e}^{2}+f \sigma_{R F}{ }^{2}+(r f / f-1) \sigma_{F Y}{ }^{2}+r y \Sigma F^{2} /(f-1)$ \\
R $\times \mathrm{F}$ & $(r-1)(f-1)$ & $\sigma_{e}^{2}+f \sigma_{R F}^{2}$ \\
Year $(Y)$ & $(y-1)$ & $\sigma_{e}^{2}+f \sigma_{R Y}{ }^{2}+r f \sigma_{Y}^{2}$ \\
F $\times Y$ & $(f-1)(y-1)$ & $\sigma_{e}^{2}+(r f / f-1) \sigma_{F Y}^{2}$ \\
R $\times Y$ & $(r-1)(y-1)$ & $\sigma_{e}^{2}+f \sigma_{R Y}{ }^{2}$ \\
Error $(\mathrm{RFY})$ & $(r-1)(f-1)(y-1)$ & $\sigma_{c}^{2}$ \\
\hline
\end{tabular}

is an allogamous and self-incompatible species susceptible to severe inbreeding depression. Decreased hetrozygosity and hetrogenicity of populations will decrease vigor and productivity.

The year $x$ half-sib family interaction effect was found to be highly significant $(\mathrm{P}<0.01)$ for all traits. However, the half-sib family effect for these traits remained significant when tested against the interaction.

Phenotypic correlation coefficients for evaluated traits are presented in Tab. 4. PFW showed strong and positive correlations with PDW. The correlation coefficient of PFW with PH was 0.624 and Annicchiarico (2006) in his

Tab. 3. ANOVA of the different sources of variation in 30 halfsib families of alfalfa

\begin{tabular}{|c|c|c|c|}
\hline Trait & $\begin{array}{l}\text { Half-sib } \\
\text { family }\end{array}$ & Year & $\begin{array}{c}\text { Half-sib } \\
\text { family x year }\end{array}$ \\
\hline Plant Fresh Weight & $* *$ & ns & $* *$ \\
\hline Plant Dry Weight & ** & ns & $* *$ \\
\hline Plant Height & ** & ** & $* *$ \\
\hline $\begin{array}{l}\text { Leaf Fresh Weight/ } \\
\text { Stem Fresh Weight }\end{array}$ & $* *$ & $* *$ & $* *$ \\
\hline $\begin{array}{l}\text { Leaf Dry Weight/ } \\
\text { Stem Dry Weight }\end{array}$ & ** & ** & ** \\
\hline d.f. & 29 & 2 & 58 \\
\hline
\end{tabular}

$\mathrm{Ns},{ }^{* *}$ : not significant and significant at the 0.01 level, respectively; d.f.: degrees of freedom

Tab. 4. Pearson's correlation coefficients between plant traits in alfalfa

\begin{tabular}{ccccc}
\hline Trait $^{\Delta}$ & PDW & PH & LFW/SFW & LDW/SDW \\
\hline PFW & $0.969^{* *}$ & $0.624^{* *}$ & $0.161^{* *}$ & $0.230^{* *}$ \\
PDW & & $0.627^{* *}$ & $0.164^{* *}$ & $0.235^{* *}$ \\
PH & & & $-0.314^{* *}$ & $-0.164^{* *}$ \\
LFW/SFW & & & & $0.938^{* *}$ \\
\hline
\end{tabular}

$\Delta_{\text {: }}$ PFW $=$ Plant Fresh Weight, PDW= Plant Dry Weight, PH= Plant Height, LFW/SFW = Leaf Fresh Weight / Stem Fresh Weight, LDW/SDW= Leaf Dry Weight/Stem Dry Weight; ${ }^{* *}$ : Significant at $\mathrm{P}<0.01$.

Tab. 5. Narrow -sense heritability values and expected responses to selection ( $\mathrm{i}=0.30 \%$ and $\mathrm{k}=1.16)$ and percentage increases of traits compared with the mean of the whole population for each trait

\begin{tabular}{cccc}
\hline Trait & $\begin{array}{c}\text { Heritability } \\
(\%)\end{array}$ & E.R. $^{\Delta}$ & $\begin{array}{c}\text { P.I. }^{*} \\
(\%)\end{array}$ \\
\hline Plant Fresh Yield (t/ha) & 51 & 3.20 & 18.0 \\
\hline Plant Dry Yield (t/ha) & 50 & 1.58 & 17.5 \\
Plant Height (cm) & 46 & 3.86 & 5.0 \\
\hline $\begin{array}{l}\text { Leaf Fresh Weight/ } \\
\text { Stem Fresh Weight }\end{array}$ & 11 & 0.0033 & 0.68 \\
$\begin{array}{c}\text { Leaf Dry Weight/ } \\
\text { Stem Dry Weight }\end{array}$ & 19 & 0.0063 & 1.4 \\
\hline
\end{tabular}

${ }^{\Delta}$ E.R. $=$ Expected Response, ${ }^{*}$ P.I. $=$ Percentage Increase 
112

study on alfalfa reported similar results. LFW/SFW and LDW/SDW, as an indicator of forage quality, were positively and significantly correlated with PFW and PDW but correlations weren't that high. The negative correlation found between plant height and quality traits (LFW/ SFW and LDW/SDW). These types of correlations were also observed by Monirifar et al. (2000) in alfalfa.

General combining ability for plant fresh and dry weight, plant height and leaf dry weight to stem dry weight showed that the parent of 'Satellou' (7), 'Garaounjeh' (30). 'Almard' (24), 'Leghan' (3), 'Baftan' (21), 'Khaje' (23), 'Sivan' (5), 'Ilan-jough' (22), 'Dizaj-safarali' (25), 'Khosrovang' (27) and 'Garababa' (13) half-sib families had the best combining abilities with others. Dudley (1963) using partial diallel showed that general combining ability for yield and relation traits are significant.

Dudley and Moll (1969) studied genetic variance in Cherokee alfalfa and showed specific combining ability for none of traits were significant. Hill (1983) reported that additive variance was significant for forage yield in alfalfa. Rooney et al. (1997) showed general combining ability for quality traits of alfalfa are significant and specific combining ability weren't significant for all traits except one.

The narrow sense heritability values based on a family mean basis and expected response to selection are given in Tab. 5.

The selection gain anticipated from recombining best parents based on half sib families was found to be $18 \%$, $17.5 \%, 5 \%, 0.68 \%$ and $1.4 \%$ for, leaf fresh weight/ stem fresh weight and leaf dry weight/stem dry weight, respectively. This indicates there are good potentials for improving plant fresh yield, plant dry yield and plant height.

Plant fresh yield and LFW/SFW as compared with rest of traits had the highest and lowest heritability, respectively. The order of heritability values among traits was PFY $>$ PDY $>$ PH $>($ LDF $/$ SDW $)>($ LFW $/$ SFW $)$. LFW/ SFW and LDW/SDW had low narrow-sense heritability, therefore showed less gains.

\section{Conclusions}

Results of this investigation indicated that correlation coefficient among alfalfa main traits were significant. The ANOVA indicated highly significant half-sib family effect on all the traits evaluated. Thus, there is a good potential to improve this populations. The progenies of ecotypes like 'Satellou', 'Gara-yonje'h, 'Almard', 'Leghan', 'Baftan', 'Khaje,' 'Sivan,' 'Ilan-jough,' 'Dizaj-safarali,' 'Khosrovanagh' and 'Gara-baba' were significantly superior in yield and related traits and they can be recommended to have higher for combining abilities. This research will be continued with combining 11 selected ecotypes to improve some synthetic varieties.

\section{Acknowledgements}

The author would like to express gratitude to Prof. Hamdollah Kazemi-arbat for useful suggestion and assist on literary editing of the paper. The research was supported by Iranian Agriculture, Research, Education and Extension Organization, AREEO and Seed and Plant Improvement Institute, SPII.

\section{References}

Aastveit AH, Aastveit K (1990). Theory and application of open-pollination and polycross in forage grass breeding. Theor Appl Genet 79:618-624.

Annicchiarico P (2006). Diversity, genetic structure, distinctness and agronomic value of Italian lucerne (Medicago sativa L.). Euphytica 148:269-282.

Barcaccia G, Albertini E, Tavoletti S, Falcinelli M, Voronesi F (1999). AFLP fingerprinting in Medicago spp.: Its development and application in linkage mapping. Plant Breeding 118(4):335-340.

Bolanos-Aguilar ED, Huyghe C, Julier B, Ecalle C (2000). Genetic variation for seed yield and its components in alfalfa (Medicago sativa L.) populations. Agronomia 20:333-345.

Bowley SR, Christie BR (1981). Inheritance of dry matter yield in a heterozygous population of alfalfa. Can J Plant Sci 61:313-318.

Dudley JW (1963). Effects of accidental estimates of general and specific combining ability in alfalfa. Crop Sci 3:517-519.

Dudley JW, Moll RH (1969). Interpretation and use of estimates of heritability and genetic variances in plant breeding. Crop Sci 9:257-262.

Dukic D (1992). Genetic variability in seed yield in lucerne. Savremena Poljoprivreda 40:69-73.

Falconer DS (1983). Introduction to quantitative genetics. 2nd ed. Longman Group Limited, New York.

Gasaneko LS, Filatova OD (1980). Fodder yield of synthetic lucerne populations. Visnik-sil's'kogospod.-nauki 1:26-27.

Goplen B, Gossen B (1994). AC Nordica alfalfa. Can J Pl Sci 74:145-147.

Halagic S, Gasperov S, Kolic B, Lovers L (1992). Trends in breeding perennial herbage crops. Sjemenarstvo 9:265-268.

Hill Jr RR (1983). Heterosis in population crosses of alfalfa. Crop Sci 23:48-50.

Martzinger DF, Kemp Thorne O (1956). The modified diallel table with partial inbreeding and interactions with environments. Genetics 41:822-833.

Monirifar $\mathrm{H}$, Valizadeh M, M Moghaddam M, Khoie FR (2000). The effects of seedling selection on mature plant traits in alfalfa (Medicago sativa L.). Turkish Journal of Field crops 1:16-21. 
Nguyen HT, Sleper DA (1983). Theory and application of half- Tucak M, Popovic S, Cupic T, Grljusic S, Bolaric S, Kozumplik sib matings in forage breeding. Theor Appl Gen 64:187196.

Rooney WL, Skinner DZ, Fritz JO (1997). Combining ability for protein degradability in alfalfa. Crop Sci 37:128-131.

SAS Institute Inc (1995). SAS language and procedure: usage, version 6, 1st ed. SAS institute, Cary, NC, USA.

Smolikova M, Nedbalkova B, Pelikan J, Ptackova M, Bystricka A (1991). Selection of lucerne genotypes for synthetic populations. Scientific Studies. OSEVA. Breeding Institute for Fodder Plants. V (2008). Genetic diversity of alfalfa (Medicago spp.) estimated by molecular markers and morphological characters. Periodicum Biologorum 110(3):243-249. 